\title{
Um caso clínico de linfoma de células do manto
}

Elisabete Pinto Borges,* Maria João Pinheiro, ${ }^{* *}$ Daniela Moreira***

\section{RESUMO}

Introdução: Os linfomas não Hodgkin constituem um grupo variável de neoplasias do sistema linforreticular que por vezes podem ser difíceis de diagnosticar. Neste caso clínico apresenta-se um tipo raro de linfoma, com forma de apresentação rara, em que o médico de família teve um papel importante no diagnóstico.

Descrição de caso: Homem de 73 anos que inicialmente se apresenta com tumefação supra-orbitária e queixas de sensação de pressão ocular, sem outros sintomas. É avaliado por oftalmologia, sendo considerado que as tumefações resultariam de tecido adiposo. Após agravamento de tumefação orbitária, surgimento de edema dos lábios e adenopatias cervicais suspeitou-se de doença linfoproliferativa. $O$ utente é referenciado para consulta de medicina interna e chega-se ao diagnóstico de linfoma de células do Manto, após excisão e análise histológica de adenopatia.

Comentário: Este caso clínico ilustra a dificuldade no diagnóstico que pode acarretar um linfoma não Hodgkin, dada a sua grande variabilidade de apresentações. O acompanhamento do doente ao longo das várias consultas foi essencial para se colocar a hipótese de diagnóstico de doença linfoproliferativa.

Palavras-chave: Linfoma; Células do Manto; não Hodgkin.

\section{INTRODUÇÃO}

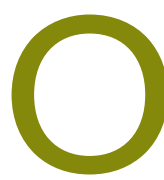

s linfomas não Hodgkin (LNH) constituem um grupo muito heterogéneo de neoplasias do sistema linforeticular. Esta heterogeneidade e a variabilidade de manifestações podem dificultar o diagnóstico e consequentemente atrasar a instituição de terapêutica. $O$ caso clínico que se expõe é ilustrador dessa dificuldade já que descreve um tipo raro de LNH, o linfoma de células do manto (a taxa de incidência de linfoma de células do manto em 13 anos, nos Estados Unidos, foi de apenas 0,55 por 100.000 habitantes). ${ }^{1}$ A forma de apresentação deste LNH foi o envolvimento orbitário bilateral, que também ela constitui uma entidade rara, uma vez que o LNH orbitário corresponde apenas a $4,5 \%$ de todos os $\mathrm{LNH}^{2-3}$

Neste caso clínico, o médico de família teve um papel fundamental para o diagnóstico ao realizar a integração de todos os dados clínicos (observação por outras especialidades, evolução clínica, exames complementares de diagnóstico). O objetivo da apresentação

* Médica Interna de Medicina Geral e Familiar, USF Viriato em Viseu

**Médica Interna de Medicina Geral e Familiar, USF Viriato em Viseu

***Médica Assistente de Medicina Geral e Familiar, USF Viriato em Viseu deste caso clínico é alertar para a suspeição diagnóstica desta patologia para que, em futuras manifestações deste tipo de linfoma, seja mais fácil o seu reconhecimento e, desta forma, seja feito um encaminhamento mais precoce para os cuidados de saúde secundários.

\section{DESCRIÇÃO DE CASO}

Homem de 73 anos, raça caucasiana, casado, pertencente a uma família nuclear na fase VIII do ciclo de Duvall, de classe média, segundo a escala de Graffar. Antecedentes pessoais de hipertensão arterial, dislipidémia, obesidade, doença coronária (com realização de bypass coronário em 2005) e gastrectomia parcial há cerca de 20 anos por úlcera gástrica. Em consulta de hipertensão na Unidade de Saúde Familiar (USF), em dezembro de 2012, referiu aumento do volume do tecido supraorbitário bilateral acompanhado de sensação de pressão, com uma instalação insidiosa, com cerca de dois ou três meses de evolução. O utente negava traumatismo prévio e negava quaisquer outros sinais ou sintomas, nomeadamente febre, dor, ardor, prurido, secura ocular ou alterações da acuidade visual. Referia ainda que a sensação de pressão orbitária era constante e não apresentava fatores de alívio ou agravamento. 
Ao exame objetivo apresentava tensão arterial controlada (125mmHg de tensão arterial sistólica e $78 \mathrm{mmHg}$ de tensão arterial diastólica), não apresentava alterações na auscultação cardiopulmonar, nem adenopatias palpáveis ao nível das cadeias ganglionares cervicais (anterior e posterior), occipitais, retroauriculares, submandibulares e supraclaviculares e a palpação da tiroide era também normal. No exame do tecido supraorbitário bilateral, a coloração cutânea era normal e à palpação notava-se uma tumefação de consistência fibroelástica, sem queixas ou dor associada. O restante exame físico não revelava quaisquer outras alterações.

Face às queixas apresentadas, colocaram-se como hipóteses de diagnóstico um hipotiroidismo, uma insuficiência renal ou uma doença de Graves, embora estas fossem consideradas hipóteses pouco prováveis, uma vez que o utente não tinha quaisquer outros sintomas além das tumefações orbitárias e estas também não eram exuberantes. Ainda assim, pediram-se análises com hemograma, função hepática, renal e tiroideia e referenciou-se o doente para uma consulta de oftalmologia (que o utente preferiu recorrer particularmente). Em março de 2013, o utente vem novamente à consulta trazendo informação da consulta de oftalmologia, da qual tinha tido alta, com a indicação de que a tumefação supraorbitária se trataria eventualmente de tecido adiposo, não tendo sido detetadas outras alterações, sendo por isso aconselhada a referenciação a uma consulta de cirurgia plástica para correção da anomalia. O estudo analítico que tinha sido pedido também não revelou quaisquer alterações e o exame físico era sobreponível ao realizado na última consulta. $\mathrm{O}$ utente mantinha-se sem outros sintomas. Negava perda ponderal, sudorese noturna, febre, queixas álgicas, alterações gastrointestinais, queixas respiratórias e queixas genito-urinárias.

Um mês depois vem a uma consulta de agudos por ter iniciado nesse dia, de forma súbita, após toma da medicação da manhã (bisoprolol 5mg e nifedipina 30mg), tumefação exuberante do lábio inferior e agravamento acentuado das tumefações supraorbitárias, novamente sem outros sintomas associados; ao exame físico apresentava-se eupneico, normotenso e apirético. Face ao quadro clínico, e dada a sua instalação súbita, foi colocada a hipótese de se tratar de um angio- dema e referenciou-se ao serviço de urgência (SU) do Centro Hospitalar Tondela Viseu (CHTV). No SU corroborou-se o diagnóstico de angioedema e o utente teve alta, medicado com anti-histamínico e com indicação de substituir a nifedipina $30 \mathrm{mg}$ por valsartan $80 \mathrm{mg}$ (por esta poder estar, eventualmente, na origem do quadro). Foi também feita a recomendação de eventual realização de TAC supraorbitária para melhor esclarecimento das tumefações supraorbitárias.

Uma semana depois do episódio de urgência, o utente regressa à USF com manutenção do quadro clínico, apesar do tratamento instituído; apresentava agora ao exame físico múltiplas adenopatias cervicais duras, aderentes e não dolorosas, sem quaisquer outros sintomas associados, nomeadamente febre, sudorese, queixas álgicas, gastrointestinais, respiratórias, genitourinárias ou outras. Assim, colocaram-se, como hipóteses de diagnóstico, uma doença linfoproliferativa, uma neoplasia, uma doença infecciosa como, por exemplo, infeção por vírus da imunodeficiência humana (VIH) ou uma eventual manifestação de uma doença autoimune. Foram, por isso, solicitados: ecografia do pescoço, ecografia de partes moles do tecido supraorbitário, ecografia abdominal, radiografia do tórax, estudo analítico com hemograma, função renal e hepática, Beta ${ }_{2}$-microglobulina, VS e PCR, serologias para VIH, sífilis, vírus da hepatite B, citomegalovírus, toxoplasmose, proteinograma, imunoglobulinas e anticorpos antinucleares.

Em maio de 2013, o utente traz resultados dos exames complementares de diagnóstico. A ecografia do pescoço demonstrava múltiplas adenopatias hipoecóides, altamente vascularizadas, de características suspeitas e a ecografia de partes moles referia formação expansiva sólida de características semelhantes às adenopatias e muito vascularizada. A ecografia abdominal e radiografia do tórax eram normais e no estudo analítico apresentava apenas Beta $_{2}$-microglobulina discretamente elevada, de $2,4 \mathrm{mg} / \mathrm{L}$ (valores de referência entre $0,8 \mathrm{e} 2,2 \mathrm{mg} / \mathrm{L}$ ), com restantes parâmetros sem alterações (hemograma, função renal e hepática normais, VS e PCR normais, serologias para hepatite B, VIH e VDRL negativas, serologias para citomegalovírus e toxoplasmose ambas IgG positivo, IgM negativo, eletroforese de proteínas séricas normal, imunoglobulinas normais e anticorpos antinucleares negativos). Pelo 
aumento discreto da Beta ${ }_{2}$-microglobulina colocou-se como hipótese de diagnóstico uma doença linfoproliferativa e decidiu-se referenciar o utente, com pedido urgente, para a consulta de medicina interna.

Para além do pedido de consulta foi também efetuado um contacto telefónico com o colega do serviço de medicina interna para expor o caso. O utente recorreu à consulta e foi posteriormente internado para estudo, em colaboração com a hematologia. Durante o internamento, o utente manteve-se sem outros sintomas, porém, foi desenvolvendo novas adenopatias, nomeadamente a nível inguinal. Realizou TAC orbitário que mostrou um exuberante aumento das glândulas lacrimais com desvio medial dos músculos retos laterais e proptose bilateral de grau II/III e realizou também medulograma que não mostrou alterações. Só após excisão cirúrgica de adenopatia inguinal, respetiva análise histológica e imunofenotipagem foi possível obter-se o diagnóstico de linfoma de células do manto da variante de pequenas células.

Atualmente o utente encontra-se a realizar ciclos de quimioterapia e mantém-se clinicamente estável.

\section{COMENTÁRIO}

Este caso é um exemplo da variabilidade de manifestações clínicas que os LNH podem apresentar. Os LNH manifestam-se maioritariamente em gânglios linfáticos, mas em aproximadamente $1 / 3$ dos casos localizam-se em tecido extraganglionar, o que pode ocasionar manifestações clínicas mais invulgares. ${ }^{4}$ Foi o que se verificou neste caso clínico, em que a doença se manifestou inicialmente com o envolvimento do tecido linfoide dos anexos orbitários, sem outros sinais ou sintomas acompanhantes.

Este caso traduz também a grande dificuldade de diagnóstico que esta doença pode acarretar. Como se pode observar, só após vários exames complementares de diagnóstico e várias consultas, de diferentes especialidades, se chegou ao diagnóstico.

Esta dificuldade é justificada pelo facto das lesões expansivas das órbitas poderem ocorrer em múltiplas patologias, desde afeções inflamatórias, tumorais, congénitas a alterações vasculares. ${ }^{5}$

Por outro lado, segundo a literatura, só cerca de 10 a $15 \%$ das massas das órbitas correspondem a linfomas. Neste caso, as órbitas foram o local primário do início da doença sistémica e só posteriormente houve envolvimento de várias cadeias ganglionares (cervicais e in guinais), mas também podia ocorrer apenas o envolvimento orbitário sem o acometimento de outras estruturas. ${ }^{6}$

Este é um tipo de linfoma bastante raro. Como já foi anteriormente referido, os LNH orbitários, primários ou secundários, correspondem apenas a $4,5 \%$ de todos os LNH e só $1 \%$ destes são primários.-3

O facto das tumefações orbitárias serem bilaterais apontava mais para doença sistémica, como, por exemplo, uma doença linfoproliferativa, uma doença autoimune ou mesmo uma doença infecciosa, mas a inexistência de outros sintomas no momento do exame, como febre, perda de peso e/ou suores noturnos, cansaço fácil, não faziam suspeitar do diagnóstico.

Para além de serem pouco frequentes os LNH das órbitas, o tipo histológico diagnosticado também é raro. Foi diagnosticado um linfoma de células do manto, que é um tipo de LNH que representa apenas 3 a $10 \%$ de todos os $\mathrm{LNH},{ }^{7} \mathrm{com}$ uma taxa de incidência que varia de 0,51 a 0,55 casos por 100.000 pessoas. ${ }^{8} \mathrm{O}$ linfoma de células do manto resulta de um processo linfoproliferativo das células B da zona do manto que surge habitualmente em adultos idosos (média de idades de apresentação de 60-65 anos), com predomínio no sexo masculino. ${ }^{79}$ A doença habitualmente manifesta-se por adenopatias generalizadas, sem outros sintomas, mas pode ocorrer envolvimento extraganglionar, especialmente o trato gastrointestinal, mas também o fígado, pulmão, pele, tecidos moles, glândulas salivares e órbitas. Habitualmente é um tipo de linfoma agressivo; no entanto, verificam-se cursos clínicos bastante heterogéneos, havendo casos com evolução mais indolente. ${ }^{9}$

Analisando este caso clínico, que representou um grande desafio de diagnóstico, é de salientar a importância do médico de família na integração de todos os dados clínicos (observação por outras especialidades, evolução clínica, exames complementares de diagnóstico) que foram essenciais para se chegar ao diagnóstico. A integração dos dados clínicos só foi possível graças ao caráter longitudinal e continuado da prestação de cuidados de saúde que caracteriza a medicina geral e familiar, ou seja, ao acompanhar o utente ao longo de várias consultas é possível perceber a evolução do quadro clínico e assim suspeitar de um diagnóstico. 
Outro ensinamento que se retira deste caso clínico é o de que nunca se devem desvalorizar as queixas de um utente. A presença de tumefações supraorbitárias assintomáticas e com estudo analítico normal podia levar-nos a pensar que se tratava de um quadro sem significado patológico. De facto, após a observação por oftalmologia foi considerada, como hipótese de diagnóstico, o excesso de tecido adiposo supraorbitário; porém, a evolução clínica revelou que se tratava de algo mais do que simples tecido adiposo.

Por fim, este caso clínico complexo alerta ainda para a necessidade de o médico de família estar constantemente a atualizar conhecimentos de forma a não descurar as causas menos prevalentes de sintomas comuns da prática clínica.

\section{REFERÊNCIAS BIBLIOGRÁFICAS}

1. Zhou Y, Wang H, Fang W, Romaguer JE, Zhang Y, Delasalle KB, et al. Incidence trends of mantle cell lymphoma in the United States between 1992 and 2004. Cancer. 2008;113(4):791-8.

2. Freeman C, Berg JW, Cutler SJ. Occurrence and prognosis of extranodal lymphomas. Cancer. 1972;29(1):252-60.

3. Trindade I, Almeida M, Coimbra F, Portela C, Esperança S, Marques H. Linfomas não-Hodgkin extraganglionares: uma análise retrospectiva [Extranodal non-Hodgkin's lymphomas: a retrospective study]. Med Intern. 2011;181(1):12-6. Portuguese

4. Ferri FF. Ferri's clinical advisor 2014. Philadelphia, PA: Mosby Elsevier;
2014. ISBN 9780323083744

5. Dantas AM, Monteiro ML. Doenças da órbita. Rio de Janeiro: Cultura Médica; 2002. ISBN 9788570062833

6. Garcia MM, Azevedo AF, Argolo DE. Linfoma em cabeça e pescoço: várias faces de um tumor [Lymphoma of the head and neck: many faces of a tumor]. Rev Imagem. 2008;30(3):103-11. Portuguese

7. Hoffman R, Benz Jr EJ, Silberstein LE, Heslop H, Weitz J, Anastasi J. Hematology: basic principles and practice. 6th ed. Churchill Livingstone; 2012. ISBN 9781437729283

8. Shah BD, Martin P, Sotomayor EM. Mantle cell lymphoma: a clinically heterogeneous disease in need of tailored approaches. Cancer Control. 2012;19(3):227-35.

9. McKay P, Leach M, Jackson R, Cook G, Rule S. Guidelines for the investigation and management of mantle cell lymphoma. $\mathrm{Br} J$ Haematol. 2012;159(4):405-26.

\section{CONFLITO DE INTERESSES}

As autoras declaram não ter conflitos de interesses.

\author{
ENDEREÇO PARA CORRESPONDÊNCIA \\ Elisabete Borges \\ USF Viriato \\ Av. Madre Rita de Jesus \\ 3510 Viseu \\ E-mail: elisabete.borges@gmail.com
}

Recebido em 11-09-2014

Aceite para publicação em 20-06-2015

Artigo escrito ao abrigo do novo acordo ortográfico.

\section{ABSTRACT}

\section{A CASE OF MANTLE CELL LYMPHOMA}

Introduction: The non-Hodgkin's lymphomas are a diverse group of neoplasms of the lymphoreticular system. The diagnosis is often difficult. In this case report we present a rare type of lymphoma, with a rare form of presentation, in which the family doctor had an important role to play in collating clinical information to make the diagnosis.

Case report: A 73-year-old man initially presented with supraorbital swelling and a complaint of pressure in the eye, without other symptoms. An ophthalmologist evaluated the patient and considered that the swelling arose from adipose tissue. After worsening of the orbital swelling and the appearance of swelling of the lips and cervical adenopathy, a lymphoproliferative disease was suspected. The patient was sent for an internal medicine consultation and the diagnosis of mantle cell lymphoma was made after excisional biopsy of a lymph node.

Comment: This case shows some of the difficulty encountered in diagnosing a non-Hodgkin's lymphoma, given great variability in their presentations. Close follow-up of the patient during numerous consultations was essential to make the diagnosis of a lymphoproliferative disease.

Keywords: Lymphoma; Mantle Cell; Non-Hodgkin. 